\title{
Psammomatoid ossifying fibroma with secondary aneurysmal bone cyst of frontal sinus
}

\author{
M. J. Nasser
}

Received: 16 December 2008 / Revised: 7 February 2009/Published online: 30 May 2009

(C) The Author(s) 2009. This article is published with open access at Springerlink.com

\begin{abstract}
Introduction Psammomatoid ossifying fibroma (POF) is a rare, slowly progressive tumor of the extragnathic craniofacial bones, with a tendency toward locally aggressive behavior.

Case report The pathognomonic histologic feature is the presence of spherical ossicles, which are similar to psammoma bodies.

Discussion Fibro-osseous lesions composed of POF and aneurysmal bone cyst (ABC) of the frontal sinus in a 12year-old boy is reported, followed by a literature review. Conclusion To our knowledge, this is the second case of a fibro-osseous lesion composed of ossifying fibroma with reactive $\mathrm{ABC}$ to be reported in the literature.
\end{abstract}

Keywords Frontal sinus · Psammomatoid ossifying fibroma . Aneurysmal bone cyst

\section{Introduction}

Psammomatoid ossifying fibroma (POF), also known as juvenile ossifying fibroma, is a rare tumor of the extragnathic craniofacial bones, particularly the periorbital, frontal, and ethmoid bones. It is a slowly progressive

M. J. Nasser $(\bowtie)$

Department of Neurosurgery, King Fahd University Hospital,

King Faisal University,

P.O. Box 40010, Al-Khobar 31952, Saudi Arabia

e-mail: munir1nasser@yahoo.com lesion with a tendency toward locally aggressive behavior, including invasion and destruction of surrounding tissue, bony erosion, and recurrence after surgical excision. The pathognomonic histologic feature is the presence of spherical ossicles, which are similar to psammoma bodies [1]. Here, we report POF of the frontal sinus in a 12-yearold boy associated with an aneurysmal bone cyst (ABC). Although $\mathrm{ABC}$ can occur as a secondary change in association with a number of benign and malignant bone lesions, to our knowledge, this is the second case of a fibroosseous lesion composed of ossifying fibroma and $\mathrm{ABC}$ to be reported in the literature.

\section{Case report}

A 12-year-old boy presented with progressive left eye proptosis for the last 3 years. The condition was diagnosed initially by an ear, nose, and throat surgeon as a mucocele of frontal sinus, but after endoscopic biopsy of the lesion, the pathology result was suggestive of a meningioma. So, the patient was referred to our neurosurgical care.

Computed tomography (CT; Fig. 1) and magnetic resonance imaging (MRI), plain and contrast (Fig. 2a, b,), of the skull revealed a huge cystic mass involving left frontal sinus with expansion of the lesion into the ethmoid and orbital cavities and extensive enhancement of the lesion. The patient was submitted to left frontal craniotomy.

The lesion was partly cystic and completely extradural. The anterior wall of the frontal sinus and the supraorbital part was destroyed by the tumor (Fig. 3). The tumor was excised completely (Fig. 4), and reconstruction of the supraorbital area was performed by acrylic cement that was fixed in place with screws. The patient was discharged to home a few days later without complications. 


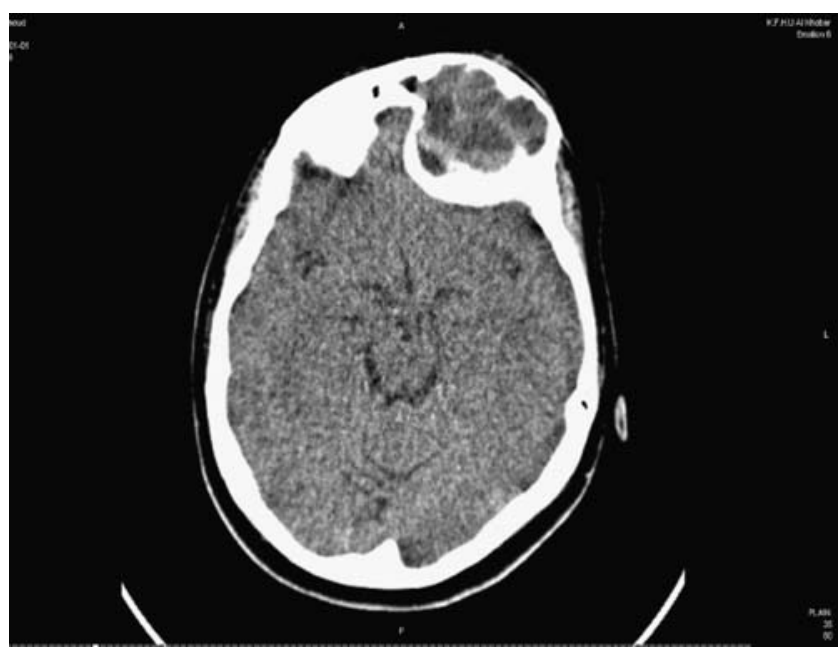

Fig. 1 Preoperative CT scan brain axial views

The material sent for histopathological study consisted of multiple grayish-white and grayish-brown tissue fragments and bone measuring $4.5 \times 4 \times 1.5 \mathrm{~cm}$ in aggregate. Microscopic examination revealed proliferated oval to spindly cells that often formed small whorls centered by calcified osteoid masses (ossicles) reminiscent of psammoma bodies (Fig. 5). The lesion was seen focally infiltrating bone. However, there was no significant nuclear pleomorphism, and mitoses could not be demonstrated. Immunohistochemically, the lesional cells showed strong and diffuse reactivity for vimentin (Fig. 6). There was no immunoreactivity for epithelial membrane antigen (EMA; Fig. 7).

The lesion was interspersed by large blood vascular spaces in areas. Osteoclastic giant cells and osteoid could be focally demonstrated in the lining of these spaces establishing the presence of an associated ABC (Fig. 8). The final diagnosis was "psammomatoid juvenile ossifying fibroma associated with an $\mathrm{ABC}$ ".

\section{Discussion}

POF was initially described by Gogl [2] in 1949 as "psammomatoid fibroma of the nose and paranasal sinuses". In 1985, Margo et al. [3] described POF as a distinctive solitary fibro-osseous lesion of young persons that affects the orbit and shows characteristic histologic features. POF has also been reported under the designations "psammous desmo-osteoblastoma" by Makek [4], "juvenile active ossifying fibroma" by Johnson et al. [5], and "juvenile ossifying fibroma" with psammoma-like ossicles by Slootweg et al. [6]. It probably arises from overproduction of the myxofibrous cellular stroma normally involved in the development of the septa in the paranasal sinuses as they enlarge and pneumatize. These stromal cells secrete hyaline material that ossifies and connective tissue mucin that initiates the cystic areas. The myxoid tissue, cystic degeneration, and aneurysmal-bone-cyst-like areas characteristic of some juvenile POF may simply be reactive changes and may not be specific for this particular lesion [7]. The majority of cases have been reported in children and young adults between 5 and 25 years of age with slight male predominance $(1.2: 1)$. The lesion is particularly common in the periorbital, frontal, and ethmoid bones. Clinical manifestations of the POF include proptosis, visual disturbances, progressive blindness, airway obstruction, headache, and progressive craniofacial deformities. Local expansion of the tumor may extend into adjacent structures, such as the paranasal sinuses, nasal cavity, nasopharynx, palate, and cranial cavity.

Our patient was a 12-year-old boy and the lesion was located in the frontal sinus. Clinically, he was presented with left eye proptosis, visual disturbances, ptosis, and disturbances in ocular mobility. Radiographic examination reveals an expansile well-circumscribed radiolucent or mixed radiolucent/radiopaque lesion surrounded by a thick bony wall [8]. CT and MRI of the skull revealed a huge cystic mass
Fig. 2 a Preoperative (plain) MRI brain T1 WI axial view. b Preoperative contrasted MRI T1 axial view
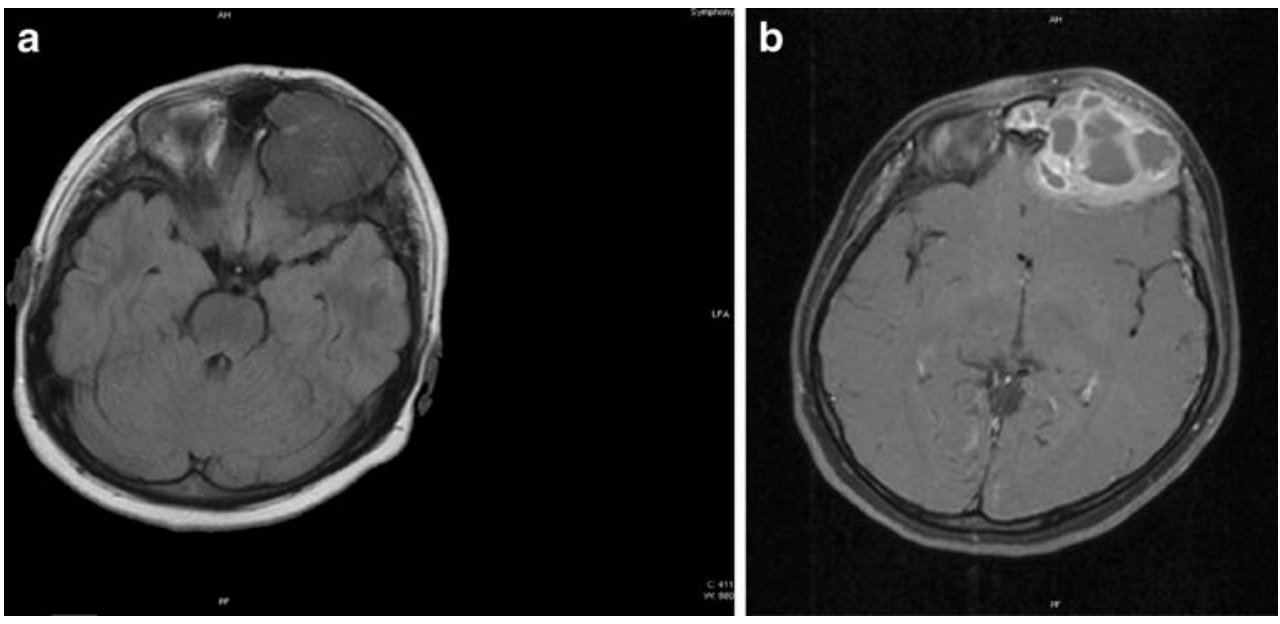


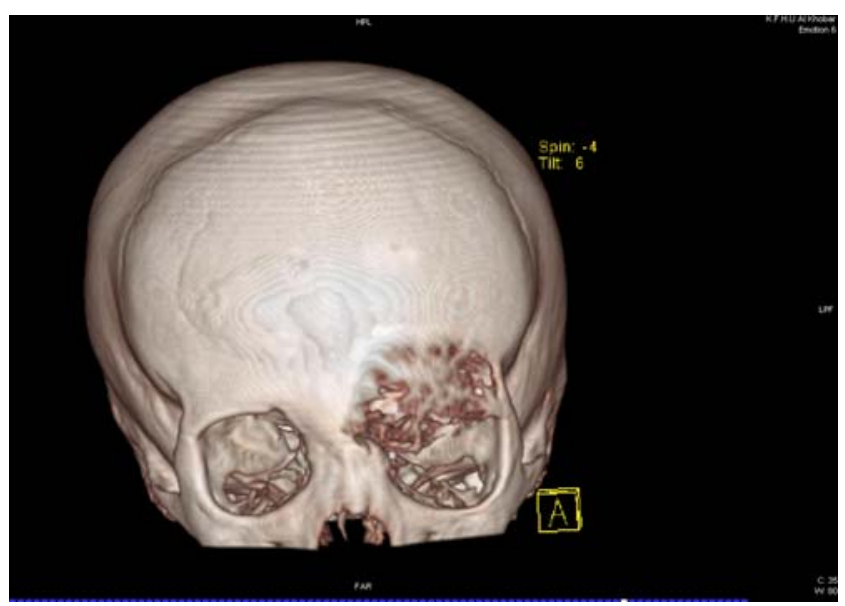

Fig. 3 3D CT scan of skull showing destroyed left supraorbital bone

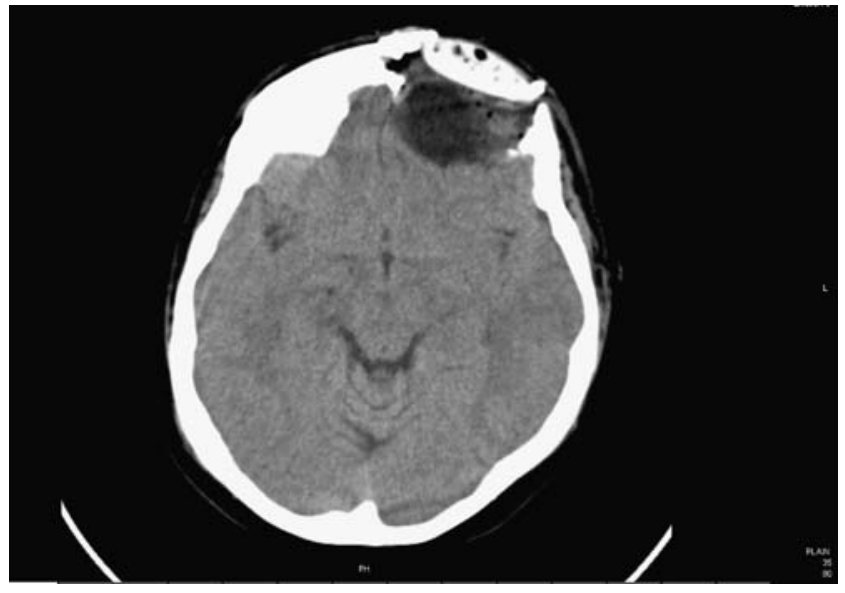

Fig. 4 Post operative CT scan brain

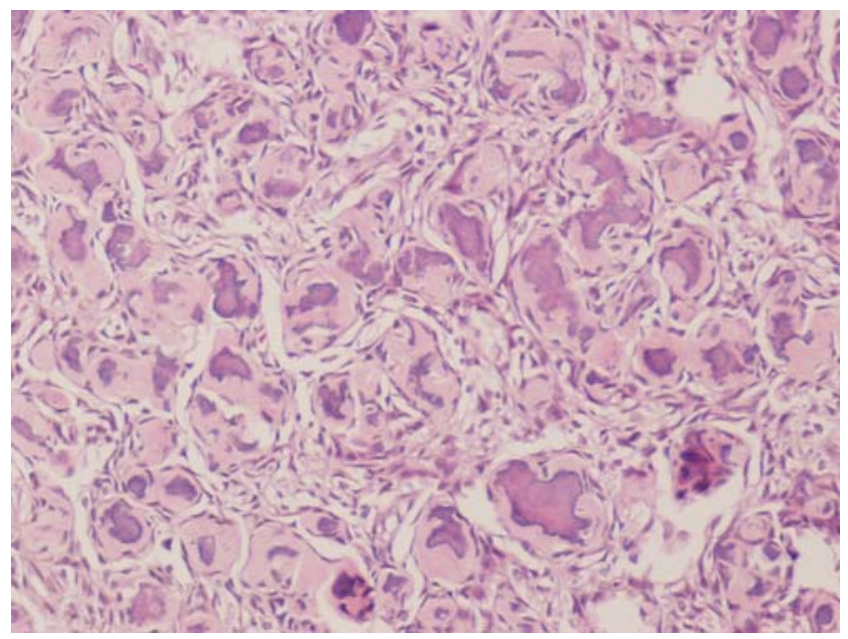

Fig.5 Microscopic view shows calcified ossicles resemble psammoma bodies

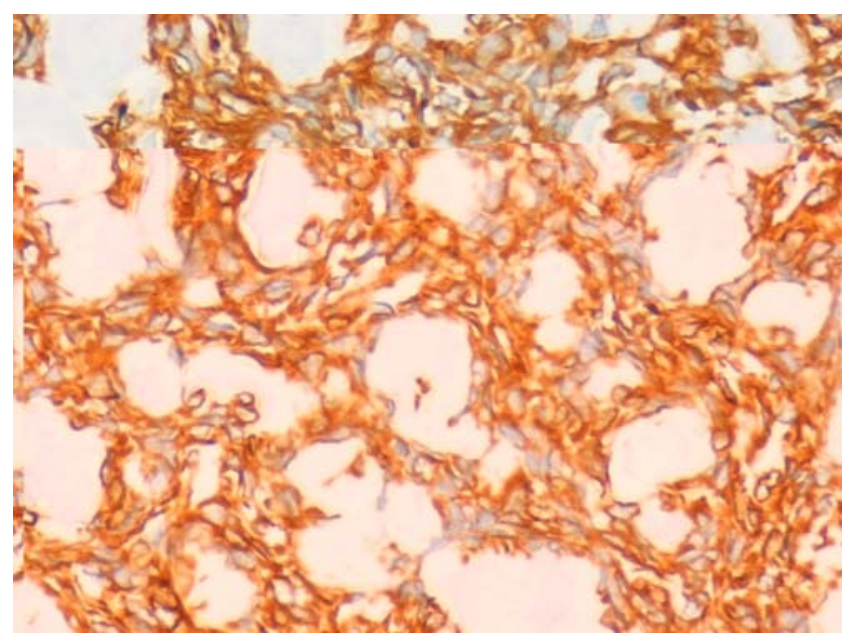

Fig.6 Immunohistochemically, cells showed strong and diffuse reactivity for vimentin

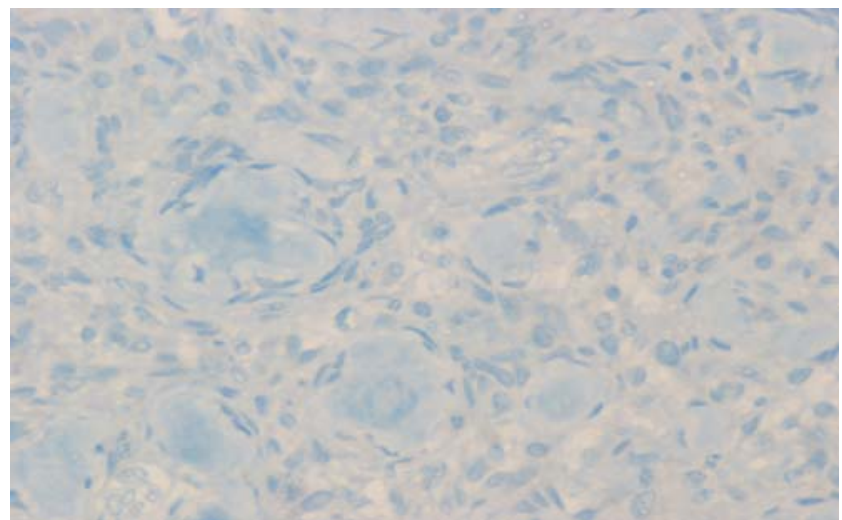

Fig.7 No immunoreactivity for EMA

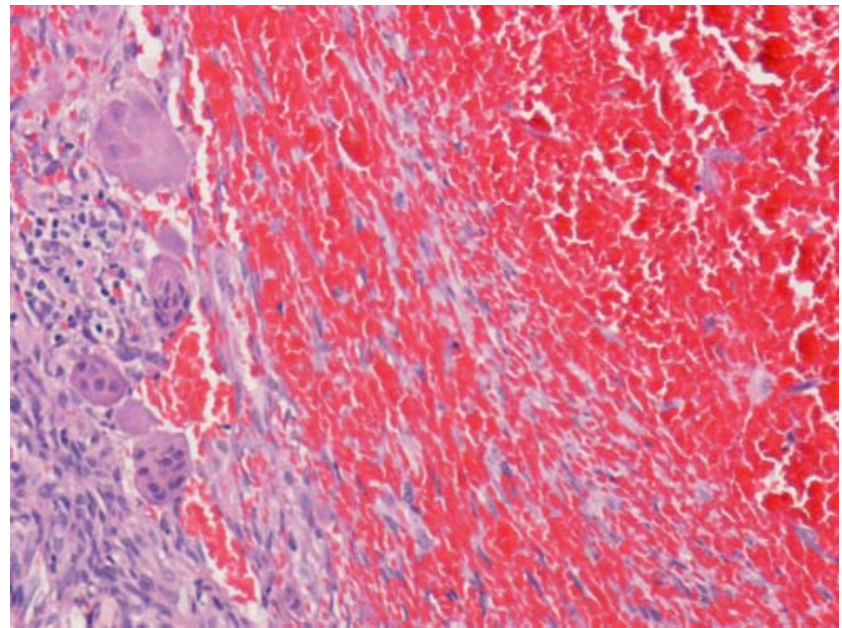

Fig. 8 Large vascular spaces 
involving left frontal sinus with expansion of the lesion into the ethmoid and orbital cavities. The cystic nature of the present lesion, which was also verified intraoperatively, may be attributed to the presence of an associated $A B C$.

Fibro-osseous lesions composed of POF and $\mathrm{ABC}$ have been previously reported [9]. The most characteristic histologic feature of POF is the presence of numerous small, round ossicles or "psammomatoid" bodies that are embedded in a cellular fibrous stroma. The ossicles are mineralized collagenous foci that vary from small, smoothly contoured round-to-oval patterns to larger, irregularly shaped patterns, with concentric layering similar to that of psammoma bodies. A prominent marginal osteoid rim surrounds the ossicles. The main histologic differential diagnosis is a primary sinonasal meningioma. The completely extradural location and the partly cystic nature of the present lesion, the young age of the patient, and the EMA negativity of the tumor cells favor the diagnosis of POF over meningioma.

\section{Conclusion}

POFs represent a unique subset of fibro-osseous lesions of the sinonasal tract. They have distinctive histomorphologic features and a tendency toward locally aggressive behavior including invasion and destruction of adjacent anatomic structures. Complete surgical removal is the treatment of choice.
Open Access This article is distributed under the terms of the Creative Commons Attribution Noncommercial License which permits any noncommercial use, distribution, and reproduction in any medium, provided the original author(s) and source are credited.

\section{References}

1. El-mofty S, St Louis (2002) Psammomatoid and trabecular juvenile ossifying fibroma of the craniofacial skeleton: two distinct clinicopathological entities. Oral Surg Oral Med Oral Pathol Oral Radiol Endo 93:296-304

2. Gogl H (1949) Das Psammo-Osteoid-Fibrom der Nase und ihrer Nebenhohlen. Monatsschr Ohrenheilkd Laryngo-Rhinol 83:1-10

3. Margo CE, Ragsdale BD, Perman KI, Zimmerman LE, Sweet DE (1985) Psammomatoid (juvenile) ossifying fibroma of the orbit. Ophthalmology 92:150-159

4. Makek MS (1987) So called "fibro-osseous lesions" of tumorous origin: biology confronts terminology. J Craniomaxillofac Surg $15: 154-167$

5. Johnson LC, Youseffi M, Vinh TN, Heffner DK, Hyams VJ, Hartman KS (1991) Juvenile active ossifying fibroma: its nature, dynamics and origin. Acta Otolaryngol 488(suppl):1-40

6. Slootweg PJ, Panders AK, Koopmans R, Nikkels PGJ (1940) Juvenile ossifying fibroma: an analysis of 33 cases with emphasis on histopathological aspects. J Oral Pathol Med 23:385-388

7. Margo CE, Ragsdale BD, Perman KI et al (1985) Psammomatoid (juvenile) ossifying fibroma of the orbit. Ophthalmology 92:150-159

8. Han MH, Chang KH, Lee CH, Seo JW, Han MC, Kim CW (1991) Sinonasal psammomatoid ossifying fibromas: CT and MRI manifestations. AJNR Am J Neuroradiol 12:25-30

9. Blayney AW, El Tayeb AA (1986) The 'hybrid' fibro-osseous lesion. J Laryngol Otol 100:291-302 